\title{
Sistem Informasi Manajemen Honorarium SMAN 1 Blanakan
}

\author{
Mochamad Rifki Yakub ${ }^{1}$, Hanhan Hanafiah Solihin ${ }^{2}$ \\ 1,2 Program Studi Sistem Informasi, Universitas Sangga Buana, Bandung, Jawa Barat, Indonesia \\ Email: rifkiyakub19@gmail.com
}

\begin{abstract}
In the current digitalization Management Information Systems era, it is essential to manage an agency; with the help of management by information technology, it can accelerate the process and reduce errors. In managing the Honorarium of SMAN 1 Blanakan, it is still carried out conventionally. It often causes errors in data input, and calculating the honorarium is still not optimal, so there is a risk of errors resulting in incorrect nominal honoraria. The solution to solving the existing problems in designing and developing a web-based Honorarium Management Information System at SMAN 1 Blanakan to facilitate the management of honorarium payments. So that it can provide convenience, a structured calculation process, and reduce the occurrence of errors. This study uses the Design Science method, which produces artifacts for making applications. The initial development of the application at the data collection stage uses observations and interviews with administrative staff at SMAN 1 Blanakan to explain the process and the weaknesses to support future problem-solving. The application development stage method uses the waterfall method, which contains steps including communication, Planning, Modeling, Construction, and Deployment. Apart from the method of making this research application using design tools using the Unified Modeling Language and Entity Relationship Diagram for database design. For making applications using CodeIgniter Framework and the database side of this research using MYSQL. This research's final result is that it has produced an Honorarium Management Information System application that helps SMAN 1 Blanakan manage employee salaries more quickly and accurately, reduces errors, and can produce reports as expected.
\end{abstract}

Keywords: Management Information Systems, Honorarium, Payment Management, Design Science Method, Waterfall Method, Unified Modeling Language

\begin{abstract}
ABSTRAK
Era digitalisasi saat ini Sistem Informasi Manajemen merupakan suatu hal yang penting dalam proses pengelolaan sebuah instansi, dengan dibantunya pengelolaan oleh teknologi informasi dapat mempercepat proses dan mengurangi kesalahan. Dalam proses pengelolaan Honorarium SMAN 1 Blanakan masih dilakukan secara konvensional, sehingga masih sering menimbulkan kesalahan penginputan data, serta proses perhitungan honorarium masih belum optimal hingga berisiko terjadi kesalahan perhitungan yang mengakibatkan tidak tepatnya nominal honorarium. Solusi menyelesaikan permasalahan yang ada adalah dengan perancangan dan pembangunan Sistem Informasi Manajemen Honorarium berbasis web di SMAN 1 Blanakan untuk memudahkan pengelolaan pembayaran honorarium. Sehingga dapat memberikan kemudahan, proses perhitungan yang terstruktur, dan mengurangi terjadinya kesalahan. Penelitian ini menggunakan metode Design Science yang menghasilkan artefak untuk pembuatan aplikasi sistem informasi manajemen, awal pembangunan aplikasi pada tahap pengumpulan data menggunakan cara observasi dan wawancara kepada staf administrasi SMAN 1 Blanakan untuk menjelaskan proses yang terjadi dan apa saja yang menjadi kelemahan sehingga mendukung pemecahan masalah kedepannya, kemudian metode pada tahap pembuatan aplikasi menggunakan metode waterfall yang memuat langkah-langkah diantaranya communication, Planning, Modeling, Construction dan Deployment. Terlepas dari metode pembuatan aplikasi penelitian ini menggunakan alat bantu perancangan dengan menggunakan Unified Modeling Language serta Entity Relationship Diagram untuk perancangan database. Untuk pembuatan aplikasi menggunakan Framework CodeIgniter dan sisi database penelitian ini menggunakan MySQL. Hasil akhir pada penelitian ini yaitu telah menghasilkan aplikasi Sistem Informasi Manajemen Honorarium yang membantu SMAN 1 Blanakan dalam mengelola honor pegawai lebih cepat, akurat dan mengurangi kesalahan serta dapat menghasilkan laporan sesuai yang diharapkan.
\end{abstract}

Kata Kunci: Sistem Informasi Manajemen, Honorarium, Manajemen Pembayaran, Metode Design Science, Metode Waterfall, Unified Modeling Language 


\section{Pendahuluan}

Pemanfaatan Teknologi Informasi diharapkan dapat membantu dalam pekerjaan, pemrosesan/pengolahan data-data penting serta pelayanan sebagaimana diharapkan oleh masyarakat [1]. Perusahaan atau organisasi lebih cenderung memilih menggunakan komputer untuk membantu proses bisnis mereka, mengolah data dan menciptakan kelengkapan sebuah sistem informasi, sehingga dalam kegiatan perusahaan atau organisasi menjadi cepat dan berjalan secara efisien, terstruktur dan fleksibel. Selain itu sistem informasi juga lebih mempermudah pekerjaan di mana dalam suatu sistem informasi terdapat masukan (input) kemudian diproses sehingga mampu menghasilkan suatu informasi yang berguna bagi penerimanya.

Upaya meningkatkan kualitas siswa-siswi SMAN 1 Blanakan agar mampu bersaing dengan lulusan sekolah lain, harus didukung oleh tenaga pengajar yang andal, teknologi pengolah data, dan manajemen pengelolaan sumber daya yang akan melayani kegiatan proses belajar mengajar. Sebagai aset yang sangat vital, Sumber Daya Manusia perlu ditingkatkan dengan baik, khususnya yang berhubungan dengan sistem yang mengelola kompensasi atas kinerjanya[2][3][4]. Dari penelitian sebelumnya menggunakan tools perancangan menggunakan Data Flow Diagram yang mengandalkan pola arus data bukan perilaku objek, sedangkan pada penelitian ini telah membahas dan menggunakan Unified Modeling Language yang membahas perilaku objek yang dituju, lalu pada pembangunan aplikasi telah menggunakan framework CodeIgniter untuk membangun aplikasi Sistem Informasi Manajemen Honorarium yang telah sesuai dengan tools perancangan yang sudah berbasis objek, serta belum adanya penelitian terdahulu pada objek pengelolaan honorarium di SMAN 1 Blanakan.

Honorarium merupakan balas jasa yang diberikan perusahaan atau instansi kepada pegawai, besarnya harus sesuai dengan peraturan dan prosedur yang ada[5]. Sedangkan menurut Martoyo (2000) pada Rikkie Dekas (2018) menyatakan bahwa "Pengungkapan honorarium dimaksudkan untuk memberikan upah atau gaji berbeda, tetapi bukan didasarkan pada evaluasi jabatan, namun ditentukan oleh kinerja"'[6].

Di SMAN 1 Blanakan sistem pembayaran honorarium masih menggunakan pola konvensional, sehingga dapat menimbulkan permasalahan yaitu:

1) Inputan data pembayaran honorarium masih kurang optimal sehingga akan mengakibatkan terjadinya kekeliruan penginputan data.

2) Perhitungan honorarium masih kurang optimal sehingga mengakibatkan terjadinya kesalahan perhitungan.

3) Laporan pembayaran honorarium hanya berupa file terpisah tiap bulannya, sehingga akan mengakibatkan kehilangan laporan dan sulit untuk direkap.

Dari beberapa masalah yang timbul maka didapat rumusan masalah untuk berusaha menyelesaikan permasalahan yang ada, adapun rumusan penelitian yaitu:

1) Bagaimana merancang sistem informasi khusus untuk mengelola pembayaran honorarium di SMA Negeri 1 Blanakan.

2) Bagaimana membuat sistem informasi yang mampu mencegah terjadinya kesalahan perhitungan pembayaran honorarium.

Bagaimana membuat sistem informasi yang memudahkan pengguna untuk mencari data historis atau pengarsipan dalam bentuk laporan.

\section{Kerangka Teoritis Sistem}

Lucas mendefinisikan Sistem pada Al-Bahra (2005) menyatakan bahwa, "Sistem sebagai suatu komponen atau variabel yang terorganisir, saling berinteraksi, saling bergantung satu sama 
lain dan terpadu"[7], sehingga sistem tidak dapat berjalan seperti semestinya jika salah satu komponen tidak ada atau bermasalah.

\section{Informasi}

"Informasi adalah Data yang diolah menjadi bentuk yang lebih berguna dan lebih berarti bagi yang menerimanya"[8], dengan itu informasi menjadi suatu hal yang sudah tervalidasi keakuratannya karena sudah dilakukan konfirmasi terlebih dahulu dari sebuah data sebelum menjadi sebuah informasi.

\section{Manajemen}

Manajemen menurut Malayu S.P. Hasibuan dalam Johar Arifin dalam Lukman Hakim (2019) adalah "ilmu dan seni mengatur hubungan dan peranan tenaga kerja agar efektif dan efisien membantu terwujudnya tujuan perusahaan, karyawan dan masyarakat'[9], dengan adanya ilmu manajemen suatu proses dapat terkendali dan dapat diperhitungkan kematangannya dan mencegah dari hal yang tidak diinginkan.

\section{Sistem Informasi Manajemen}

Menurut Kenneth C. Laudon dan Jane P. Laudon (2012) "Sistem Informasi Manajemen menjadikan dimana perilaku manajemen berubah, bagaimana pekerjaan diatur, terkoordinasi, dan terukur juga membuat perubahan dalam suatu organisasi. Dengan menghubungkan karyawan yang bekerja disuatu tim pada suatu jaringan sosial (internet) yang memungkinkan menjadi suatu tempat karyawan bertemu satu sama lain, merencanakan, mengkolaborasikan hingga menyelesaikan tugas tertentu, bahkan ketika mereka dipisahkan benua dan zona waktu yang berbeda"'[10]. Kunci utama pada sistem informasi manajemen adalah peran teknologi informasi dalam proses manajemen, sehingga proses akan semakin cepat dan akurat.

\section{Honorarium}

"Honorarium atau Honor atau Honoraria adalah pembayaran atas jasa yang diberikan pada suatu kegiatan tertentu. Honorarium juga dapat diberikan melalui mekanisme belanja pegawai dan belanja nonpegawai" [5].

\section{Unified Modeling Language}

Peralatan pendukung yang digunakan dalam merancang aplikasi adalah UML (Unifield Modeling Language). sebagai bahasa, berarti UML memiliki sintaks dan semantik. Ketika membuat model menggunakan konsep UML ada aturan-aturan yang harus diikuti.

Bagaimana elemen-elemen pada model yang dibuat berhubungan satu dengan lainnya harus mengikuti standar yang ada, UML diaplikasikan untuk maksud tertentu, biasanya antara lain untuk: 1. Merancang perangkat lunak.

2. Sarana komunikasi antara perangkat lunak dengan proses bisnis.

3. Menjabarkan sistem secara rinci untuk analisa dan mencari apa yang diperlukan sistem.

4. Mendokumentasikan sistem yang ada, proses-proses dan organisasinya[11].

\section{CodeIgniter}

CodeIgniter (CI) adalah framework pengembangan aplikasi (Application Development Framework) dengan menggunakan PHP, suatu kerangka kerja untuk bekerja atau membuat program menggunakan PHP yang lebih sistematis. Pemrogram tidak perlu membuat program dari awal (from scracth), karena CI menyediakan sekumpulan library yang banyak yang diperlukan untuk menyelesaikan pekerjaan yang umum, dengan menggunakan antarmuka dan struktur logika yang 
sederhana untuk mengakses library nya. Pemrogram dapat memfokuskan diri pada kode yang harus dibuat untuk menyelesaikan suatu pekerjaan[12][13].

\section{Perancangan Database}

Perancangan database merupakan perancangan yang digunakan untuk pembuatan dan penyimpanan data ke dalam sistem terdiri dari beberapa file database. Pada perancangan basis data ini akan dibahas Relasi Tabel, Entity Relationship Diagram (ERD)[14].

\section{Entity Relationship Diagram (ERD)}

Entity Relationship Diagram (ERD) adalah bentuk bagan yang menggunakan relasi dan entitas suatu informasi. Entitas relasi diagram dibuat dengan menggunakan persepsi yang terdiri dari sekumpulan objek yang ada dan dibedakan dari objek yang ada serta dibedakan dari objek lain[14].

\section{Metode}

Metode merupakan langkah penting untuk memecahkan masalah - masalah pada penelitian, metode yang digunakan adalah metode Design Science, di mana seorang desainer atau peneliti menjawab pertanyaan yang relevan dengan masalah yang ada melalui penciptaan artefak inovatif, dengan demikian memberikan kontribusi pengetahuan baru dengan bukti ilmiah. Artefak yang dirancang berguna dan mendasar dalam memahami masalah [15]. Berikut adalah gambaran pada penelitian ini dimana terbagi menjadi beberapa tahapan yaitu, tahapan pengumpulan data, metode pengembangan aplikasi sistem informasi manajemen honorarium SMAN 1 Blanakan, hasil aplikasi Sistem Informasi Manajemen Honorarium SMAN 1 Blanakan dan diakhiri dengan tahap pembuatan laporan. Adapun gambaran pada metode penelitian dapat dilihat pada gambar 1 berikut.

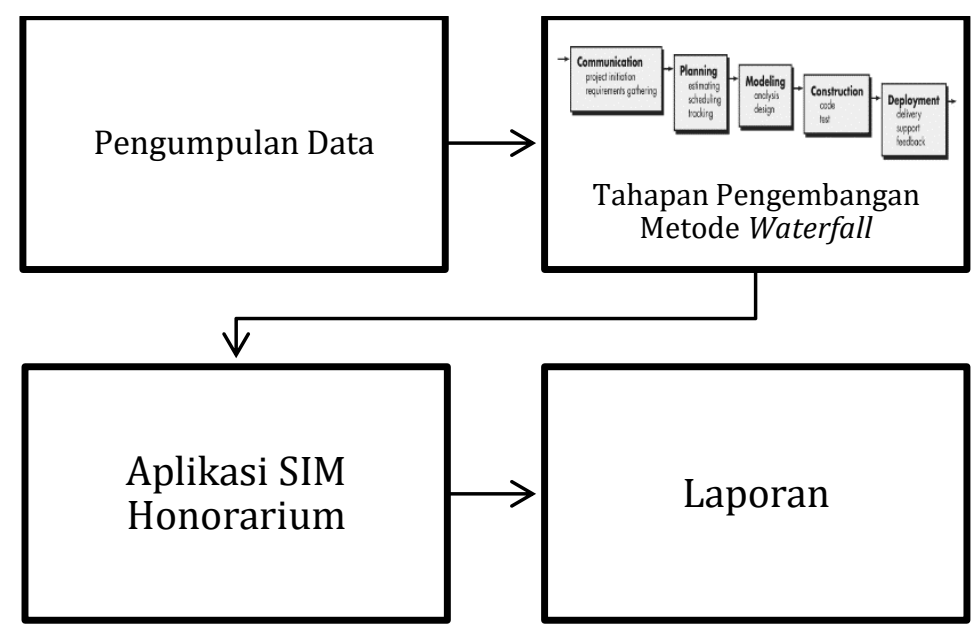

Gambar 1. Metode Penelitian

\section{Teknik Pengumpulan Data}

Teknik pengumpulan data adalah cara - cara yang dapat digunakan pada penelitian ini untuk mengumpulkan data. Penelitian ini menggunakan teknik pengumpulan data berupa sumber data primer dan data sekunder. Berikut merupakan pengumpulan data yang dilakukan:

a. Sumber data primer

Sumber data primer yang dilakukan yaitu berupa observasi. Penelitian langsung dengan mengunjungi dan melakukan wawancara dengan staf administrasi SMAN 1 Blanakan. Hal ini 
dilakukan untuk melihat secara langsung masalah yang berhubungan dengan pokok bahasan penelitian.

b. Sumber data sekunder

Sumber data sekunder dilakukan melalui dokumen. Penelitian pada sumber data sekunder dilakukan dengan mempelajari literatur yang berkaitan dengan masalah yang muncul pada objek penelitian. Dimana literatur tersebut akan digunakan sebagai dasar pemikiran dan pertimbangan dalam hal yang bersifat praktik di lapangan.

\section{Metode Pengembangan Sistem}

Metode pengembangan yang digunakan dalam merancang aplikasi sistem informasi manajemen honorarium ini yaitu menggunakan metode pengembangan waterfall. Model waterfall biasa juga disebut siklus hidup perangkat lunak. Mengambil kegiatan dasar seperti spesifikasi, pengembangan, validasi dan merepresentasikannya sebagai fase-fase proses yang berbeda seperti spesifikasi persyaratan, perancangan perangkat lunak, implementasi, pengujian dan seterusnya.

Menurut Roger S. Pressman dan Bruce R. Maxim (2015) Langkah-langkah pengembangan Sistem yang dilakukan adalah:

a. Communication: Peneliti melakukan komunikasi dengan pihak SMAN 1 Blanakan untuk coba menganalisis pola prosedur pada pengelolaan Honorarium

b. Planning: Mengestimasi apa saja prosedur dan kelemahan yang berjalan, serta kapan dapat dimulainya ketahapan berikutnya.

c. Modeling: Membuat perancangan untuk aplikasi sesuai dengan analisis dari prosedur yang berjalan, pada penelitian ini perancangan menggunakan alat bantu UML.

d. Construction: Menterjemahkan hasil perancangan dalam coding. Membuat database dengan menggunakan Mysql, membuat pemrograman PHP dengan framework CodeIgniter.

e. Deployment. Memberikan hasil program aplikasi kepada end user untuk menerima masukan tentang apa yang menjadi kekurangan aplikasi sistem [16].

Tahapan tersebut dapat dilihat pada gambar 2 berikut sesuai dari tahapan waterfall pada buku Roger S. Pressman dan Bruce R. Maxim:

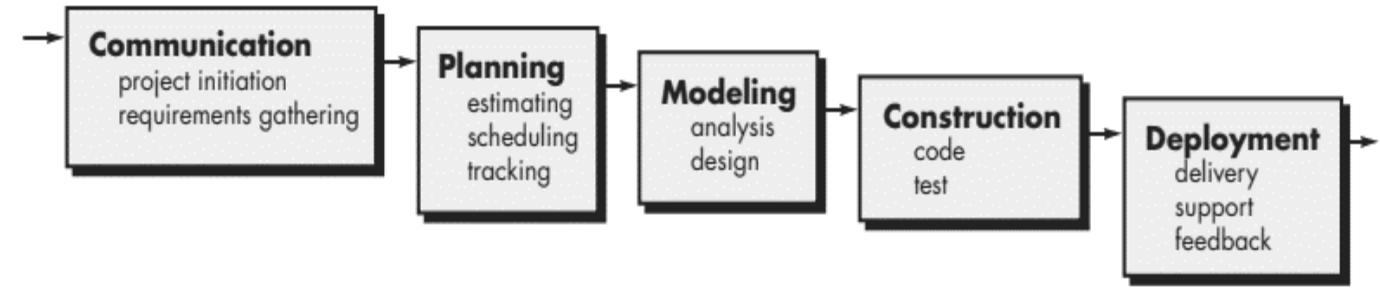

Gambar 2. Metode Waterfall [16]

\section{Aplikasi Sistem Informasi Manajemen Honorarium}

Tahapan ini merupakan hasil dari tahapan pengembangan sistem dengan metode waterfall di mana akan menghasilkan sebuah aplikasi SIM Honorarium yang sudah siap pakai.

\section{Laporan}

Tahapan terakhir pada penelitian ini adalah pembuatan laporan dari awal hingga akhir penelitian dengan tujuan agar adanya informasi histori penelitian.

\section{Hasil dan Pembahasan}

Berikut adalah hasil dari pembahasan yang meliputi rancangan aplikasi dengan use case diagram, pada kesempatan ini Activity Diagram tidak ditampilkan pada pembahasan 
dikarenakan use case diagram dirasa sudah cukup mewakili dari perancangan sistem. Sisi relasi database menggunakan entity relationship diagram, penjabaran data pada database menggunakan struktur data, antarmuka untuk merancang bagaimana rancangan tampilan aplikasi sebelum implementasi dan hasil implementasi berupa tampilan yang sudah berupa aplikasi sistem informasi manajemen honorarium SMAN 1 Blanakan.

\section{Use Case Diagram}

Use Case Diagram mendeskripsikan interaksi antara satu atau lebih aktor dengan sistem informasi yang akan dibuat. Berikut adalah Use Case Diagram dari perancangan dan pembangunan sistem informasi manajemen pembayaran honorarium pada SMAN 1 Blanakan yang dapat dilihat pada gambar 3 berikut ini.

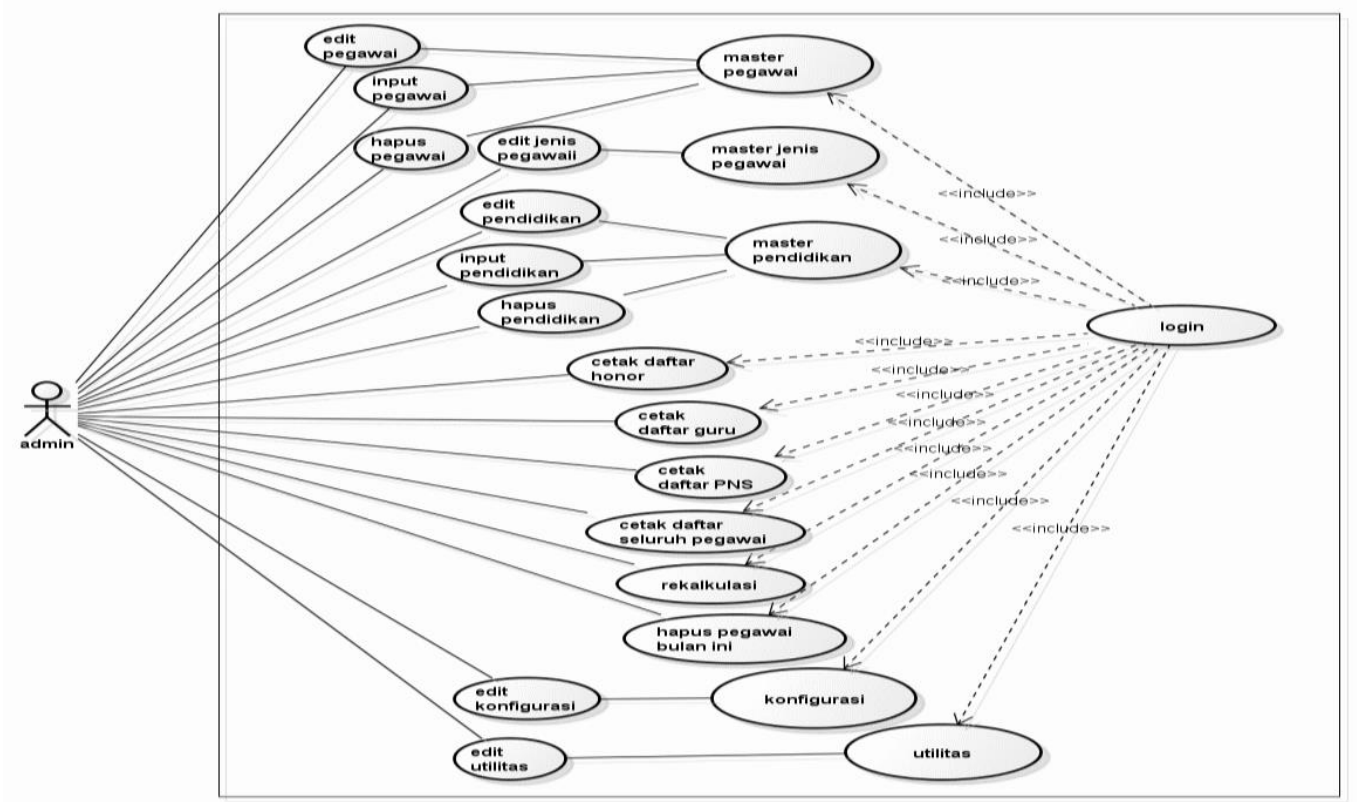

Gambar 3. Use Case Diagram Rancangan Sistem Informasi Manajemen Honorarium

\section{Entity Relationship Diagram (ERD)}

ERD adalah suatu model untuk merepresentasikan hubungan antara data dalam basis data berdasarkan entitas data yang memiliki hubungan dengan dan antar relasi. Pada gambar 4 dapat dilihat ERD untuk perancangan aplikasi Sistem Informasi Manajemen Honorarium SMAN 1 Blanakan.

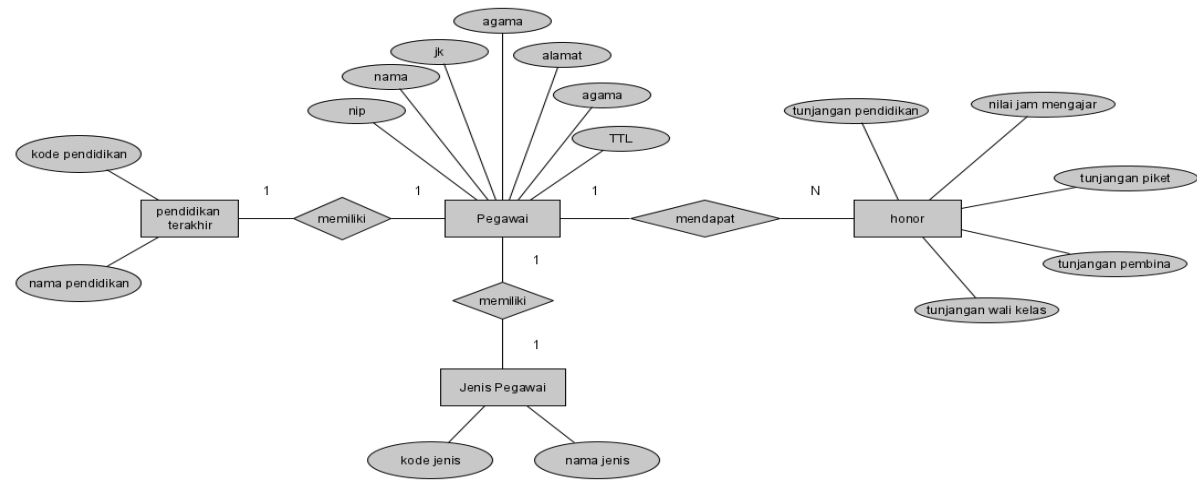

Gambar 4. Entity Relationship Diagram Sistem Informasi Manajemen Honorarium 


\section{Struktur Data}

Struktur Tabel master_pegawai yang terdapat pada tabel 1 merupakan tabel yang digunakan untuk menyimpan seluruh data pegawai, baik yang masih aktif, maupun pegawai yang sudah tidak aktif. Tabel Master_pegawai memiliki satu Primary Key yaitu field id_pegawai. Tabel ini menampung semua identitas pegawai seperti alamat, nomor telepon, dll. Berikut dapat dilihat pada tabel 1.

Tabel 1. Tabel Master Pegawai

\begin{tabular}{lll}
\hline Nama Atribut & Tipe Data & Panjang \\
\hline Id_pegawai & Int & 11 \\
Nip & Varchar & 18 \\
Nama & Varchar & 100 \\
Jk & Varchar & 1 \\
Agama & Varchar & 20 \\
Telp & Varchar & 20 \\
Alamat & Text & \\
Tempat_lahir & Varchar & 50 \\
Tgl_lahir & Date & \\
Kode_jenis & Varchar & 2 \\
Jam_mengajar & Int & 11 \\
Pegawai_prov & Varchar & 1 \\
Kode_pend & Varchar & 5 \\
Wali_kelas & Int & 1 \\
Pembina & Int & 1 \\
Piket & Int & 1 \\
Status_pegawai & Varchar & 1 \\
\hline
\end{tabular}

Tabel master_jenis_pegawai yang terdapat pada tabel 2 adalah tabel yang menampung jenis pegawai atau posisi pekerjaan di SMAN 1 Blanakan seperti Guru Honorer Tidak Tetap, Pegawai Negeri Sipil (PNS), maupun staf non guru. Tabel ini memiliki satu Primary Key yaitu field id_jenis.

Tabel 2. Tabel Master Jenis Pegawai

\begin{tabular}{lll}
\hline Nama Atribut & Tipe Data & Panjang \\
\hline Id_jenis & Int & 11 \\
Kode_jenis & Varchar & 2 \\
Nama_jenis & Varchar & 50 \\
\hline
\end{tabular}

Tabel master_pendidikan_terakhir adalah tabel yang digunakan untuk menampung pendidikan terakhir dan besaran insentif yang di terima pegawai staf non guru. Tabel ini memiliki satu Primary Key yaitu field id_pend. Dapat dilihat pada tabel 3.

Tabel 3. Tabel Pendidikan Terakhir

\begin{tabular}{lll}
\hline Nama Atribut & Tipe Data & Panjang \\
\hline Id_pend & Int & 2 \\
Kode_pend & Varchar & 5 \\
Nama_pend & Varchar & 100 \\
Tunjangan_pend & Int & 9 \\
\hline
\end{tabular}

Tabel transaksi_honor yang terdapat pada tabel 4 adalah tabel yang digunakan untuk menampung semua transaksi honorarium pegawai aktif yang dilakukan setiap bulan. 
Tabel 4. Tabel Transaksi Honor

\begin{tabular}{lll}
\hline Nama Atribut & Tipe Data & Panjang \\
\hline Id & Int & 11 \\
Periode & Varchar & 6 \\
Nip & Varchar & 18 \\
Nama & Varchar & 100 \\
Jk & Varchar & 1 \\
Kode_jenis & Varchar & 5 \\
Kode_pend & Varchar & 5 \\
Tunjangan_pend & Int & 11 \\
Jam_mengajar & Int & 2 \\
Pot_jam_mengajar & Int & 2 \\
Sisa_jam_mengajar & Int & 2 \\
Nilai_jam_mengajar & Int & 11 \\
Tunj_walikelas & Int & 11 \\
Tunj_pembina & Int & 11 \\
Tunj_piket & Int & 11 \\
Total & Int & 11 \\
\hline
\end{tabular}

Tabel konfigurasi adalah tabel yang digunakan untuk menampung data instansi yang akan digunakan pada laporan seperti nip, nama dan jabatan penandatangan, serta nama dan alamat sekolah. Dapat dilihat pada tabel 5 sebagai berikut.

Tabel 5. Tabel Konfigurasi

\begin{tabular}{lll}
\hline Nama Atribut & Tipe Data & Panjang \\
\hline Nama_sekolah & Varchar & 100 \\
Alamat_sekolah & Text & \\
Telp_sekolah & Varchar & 20 \\
Kota & Varchar & 100 \\
Tahun_ajaran & Varchar & 10 \\
Penandatangan1 & Varchar & 75 \\
Jab_penandatangan1 & Varchar & 50 \\
Nip_penandatangan1 & Varchar & 20 \\
Penandatangan2 & Varchar & 75 \\
Jab_penandatangan2 & Varchar & 50 \\
Nip_penandatangan2 & Varchar & 20 \\
Penandatangan3 & Varchar & 75 \\
Jab_penandatangan3 & Varchar & 50 \\
Nip_penandatangan3 & Varchar & 20 \\
\hline
\end{tabular}

Tabel utilitas yang terdapat pada tabel 6 merupakan tabel untuk menampung perhitungan yang sewaktu - waktu bisa berubah seperti besaran tunjangan insentif, ataupun upah mengajar per jam.

Tabel 6. Tabel Utilitas 


\begin{tabular}{lll}
\hline Nama Atribut & Tipe Data & Panjang \\
\hline Jam_prov & Int & 2 \\
Tunj_walikelas & Int & 11 \\
Tunj_pembina & Int & 11 \\
Tunj_piket & Int & 11 \\
Upah_per_jam & Int & 9 \\
\hline
\end{tabular}

\section{Perancangan Antar Muka}

Perancangan antar muka adalah perancangan tampilan setiap halaman dari sebuah sistem informasi. Gambar 5 sampai dengan gambar 10 merupakan tampilan antar muka pada sistem informasi manajemen honorarium.

Gambar 5 berikut ini menampilkan rancangan antar muka Halaman Home adalah halaman yang pertama sistem tampilkan ketika user berhasil melakukan Login. Berikut tampilan gambar halaman Home.

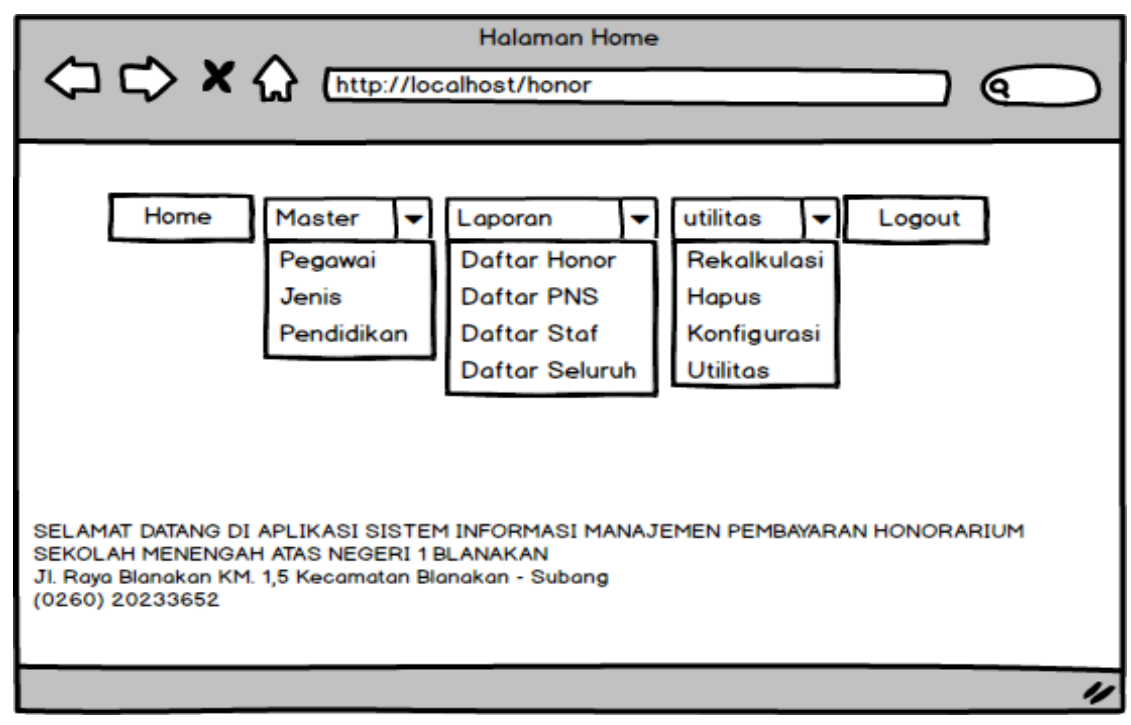

Gambar 5 tampilan halaman Home

Halaman Master Pegawai pada gambar 6 adalah menu yang menampilkan seluruh pegawai baik yang aktif maupun tidak aktif. Di menu ini user juga dapat melakukan edit, tambah, hapus dan melihat detail pegawai. Dapat dilihat sebagai berikut. 


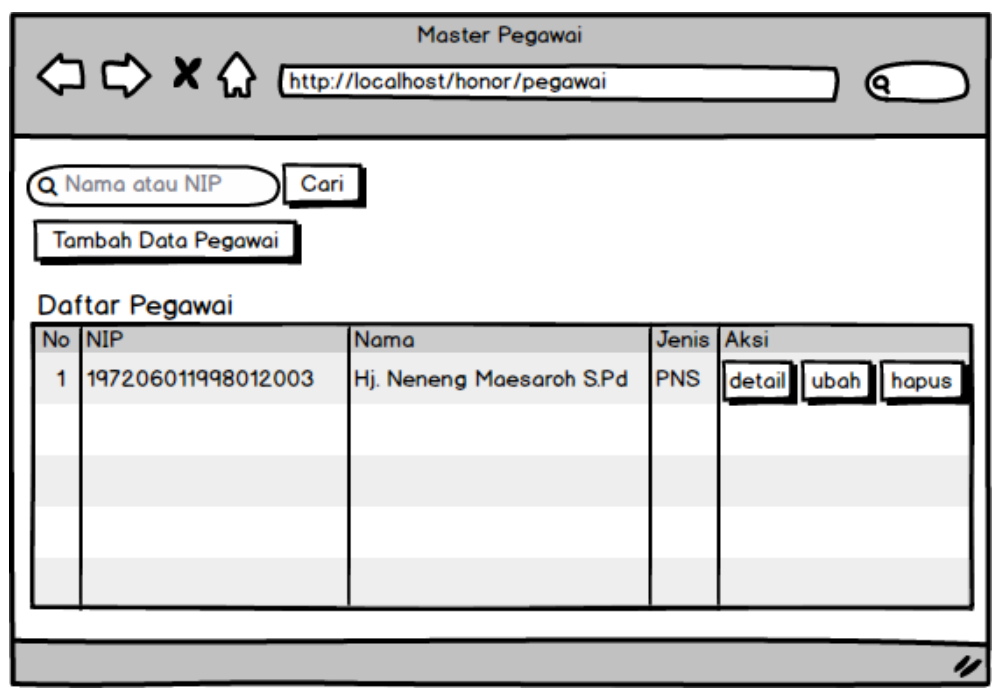

Gambar 6. Tampilan Menu Master Pegawai

Halaman Cetak Daftar Seluruh Pegawai adalah menu yang digunakan untuk mencetak daftar keseluruhan pegawai baik itu pegawai Honorer Tidak Tetap, Pegawai Negeri Sipil, maupun pegawai Staf Non-Guru. Menu ini menyajikan laporan per-bulan. Dapat dilihat pada gambar 7 sebagai berikut.

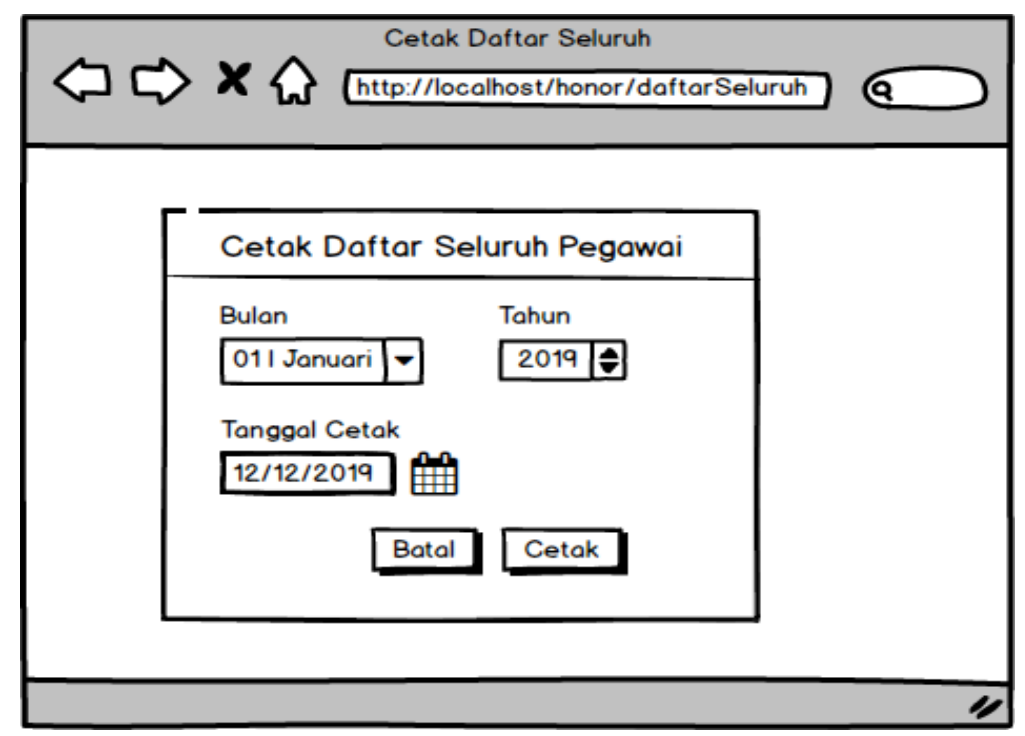

Gambar 7. Tampilan Menu Cetak Daftar Seluruh Pegawai

Halaman Rekalkulasi pada gambar 8 adalah menu yang digunakan untuk pembentukan honor bulan depan yaitu honor yang saat ini sedang di proses. Berikut tampilan rancangan antar muka halaman rekalkulasi. 


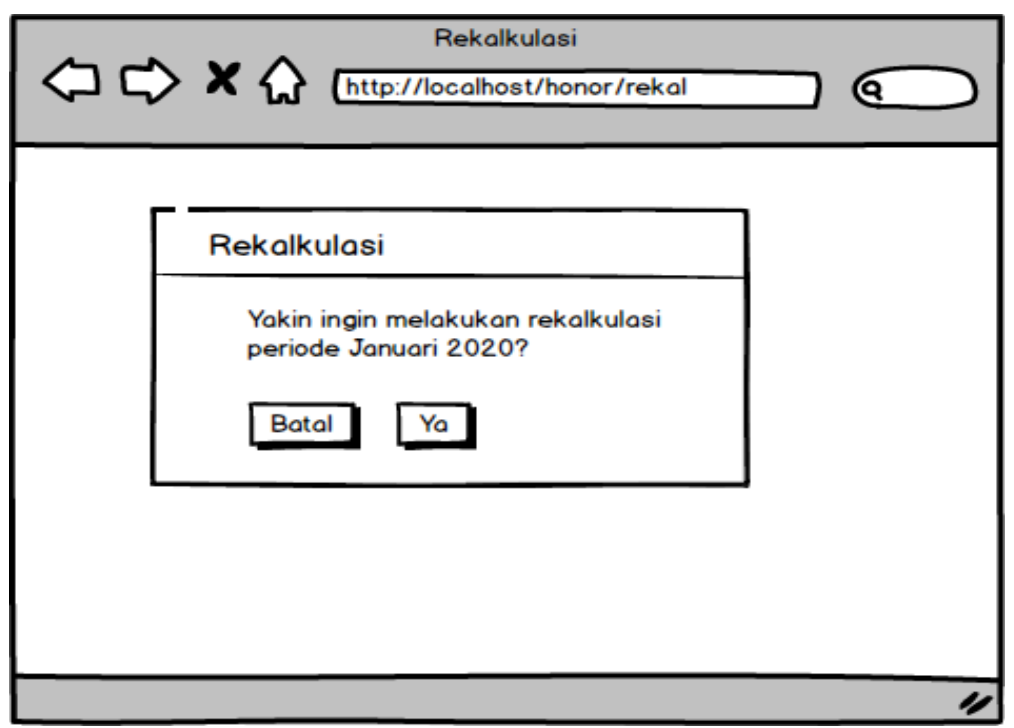

Gambar 8. Tampilan Menu Rekalkulasi

Halaman Konfigurasi adalah menu yang digunakan untuk mengatur identitas instansi yang ditampilkan di aplikasi dan laporan cetakan, seperti nama sekolah, nomor telepon sekolah, tahun ajaran serta nama, jabatan dan NIP penandatangan. Dapat dilihat pada gambar 9 sebagai berikut.

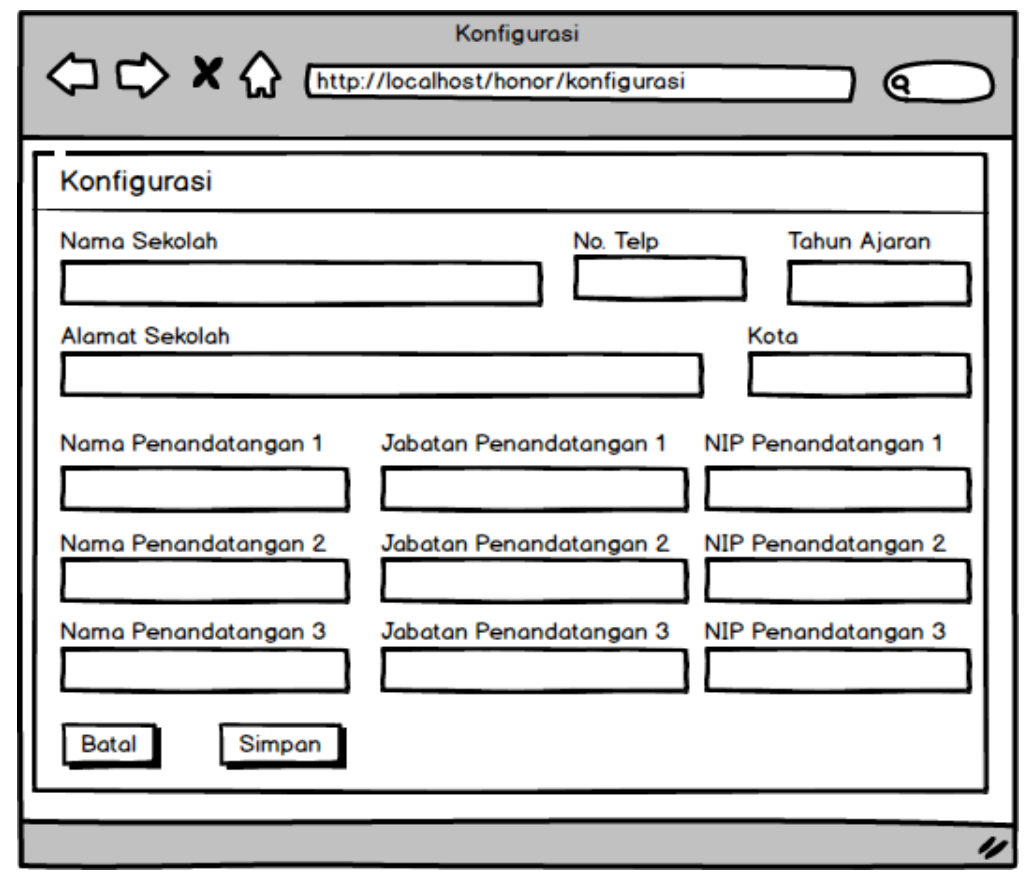

Gambar 9. Tampilan Menu Konfigurasi

Halaman Utilitas yang ditampilkan pada gambar 10 adalah menu yang digunakan untuk mengatur besaran upah yang diterima oleh pegawai, yaitu berupa insentif tunjangan wali kelas, tunjangan pembina, tunjangan piket dan upah mengajar per-jam. Berikut gambaran rancangan antarmuka halaman utilitas. 


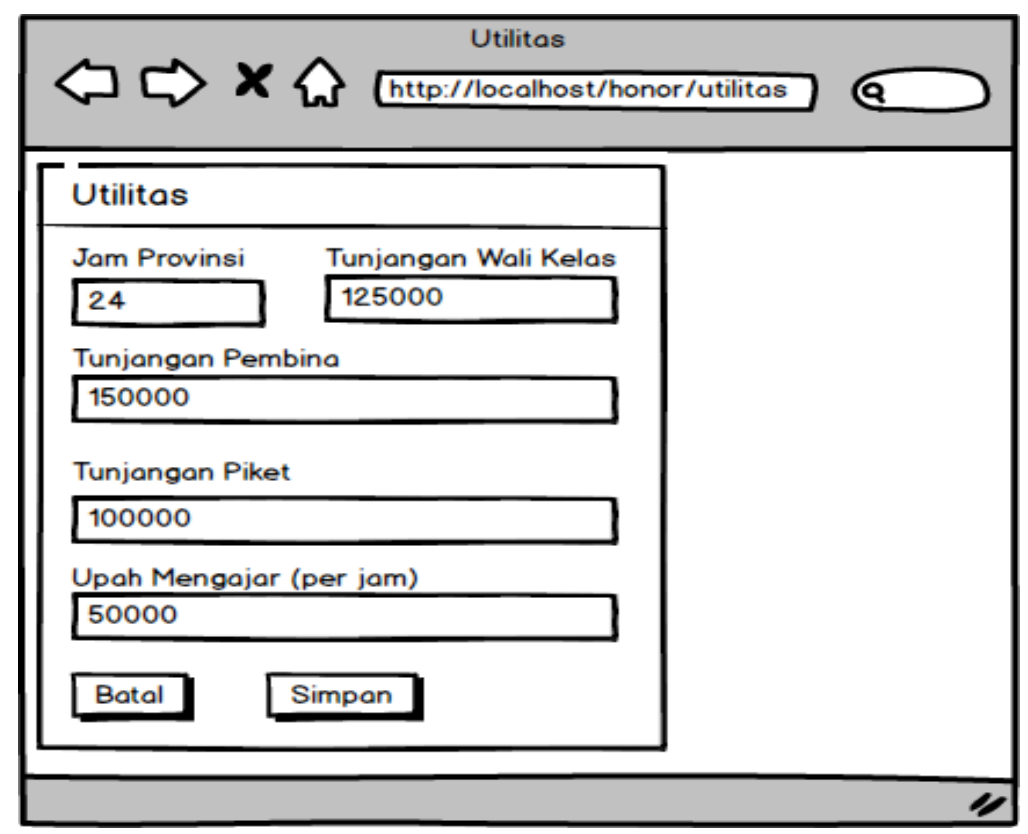

Gambar 10. Tampilan Menu Utilitas

\section{Hasil Implementasi}

Dari hasil tahap construction terutama yang didalamnya terdapat tahapan coding menghasilkan sebuah aplikasi sistem informasi manajemen honorarium dengan tampilan hasil dapat dilihat pada gambar 11 sampai gambar 16 berikut.

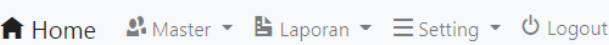

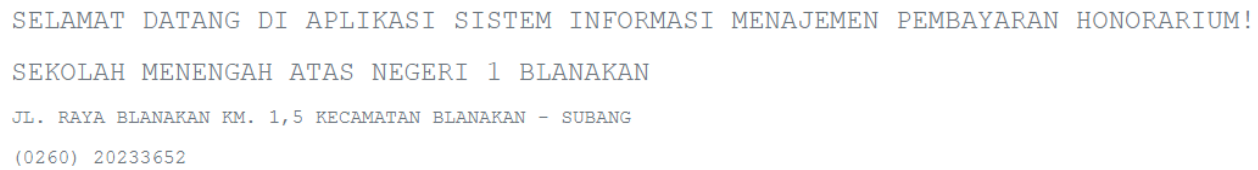

Gambar 11. Tampilan Halaman Home 
Mochamad Rifki Yakub ${ }^{1}$, Hanhan Hanafiah Solihin²

@is The Best: Accounting Information Systems and Information Technology Business Enterprise ISSN: 2252-9853 (Print) | ISSN: 2656-808X (Online)

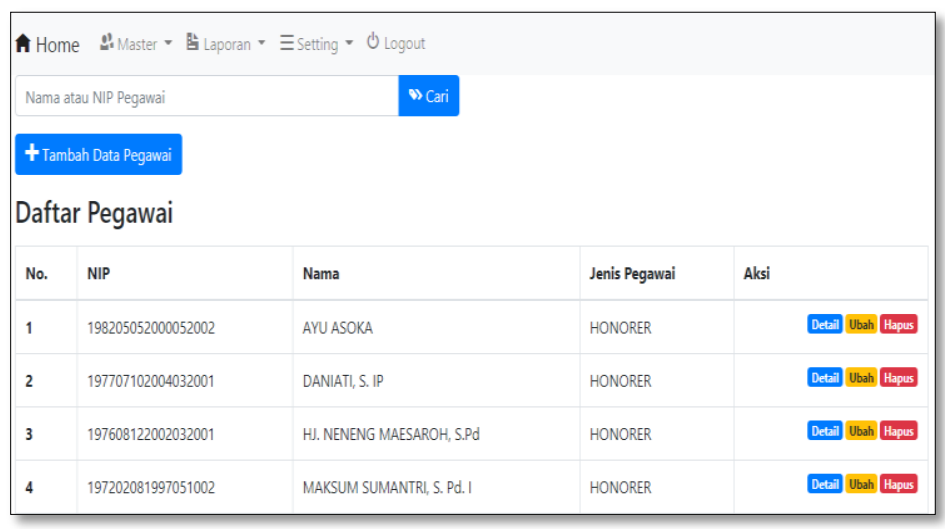

Gambar 12. Tampilan Menu Master Pegawai

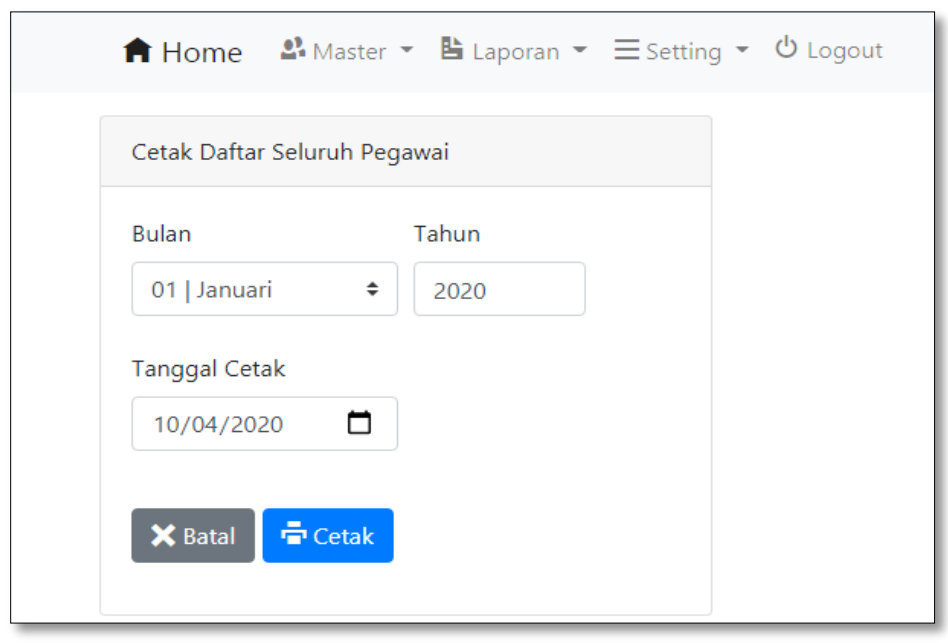

Gambar 13. Tampilan Menu Cetak Daftar Seluruh Pegawai

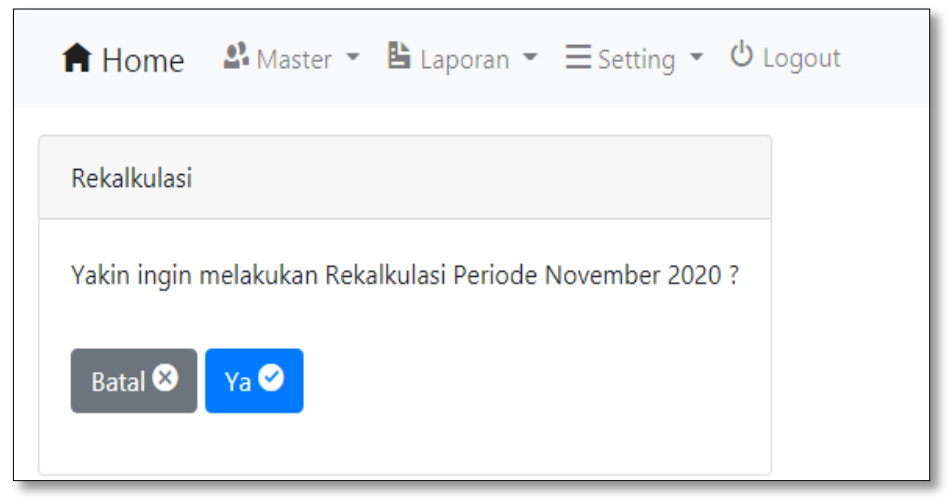

Gambar 14. Tampilan Menu Rekalkulasi 
Mochamad Rifki Yakub ${ }^{1}$, Hanhan Hanafiah Solihin²

@is The Best: Accounting Information Systems and Information Technology Business Enterprise

ISSN: 2252-9853 (Print) | ISSN: 2656-808X (Online)

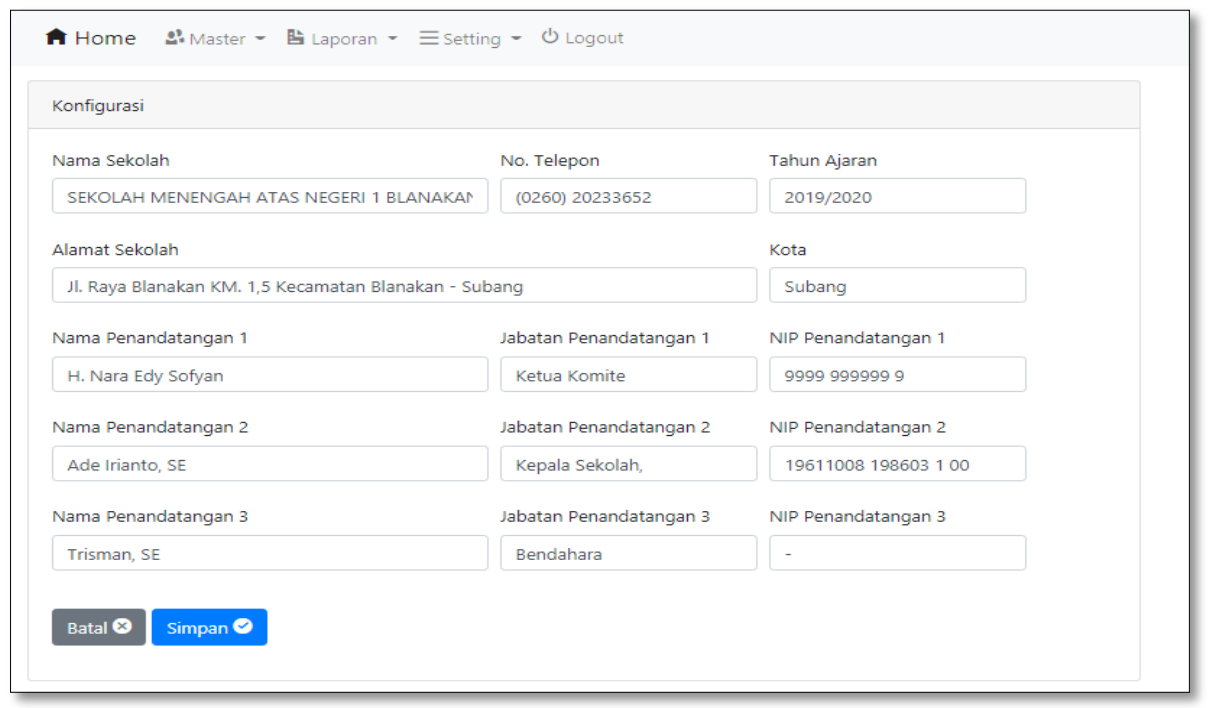

Gambar 15. Tampilan Menu Konfigurasi

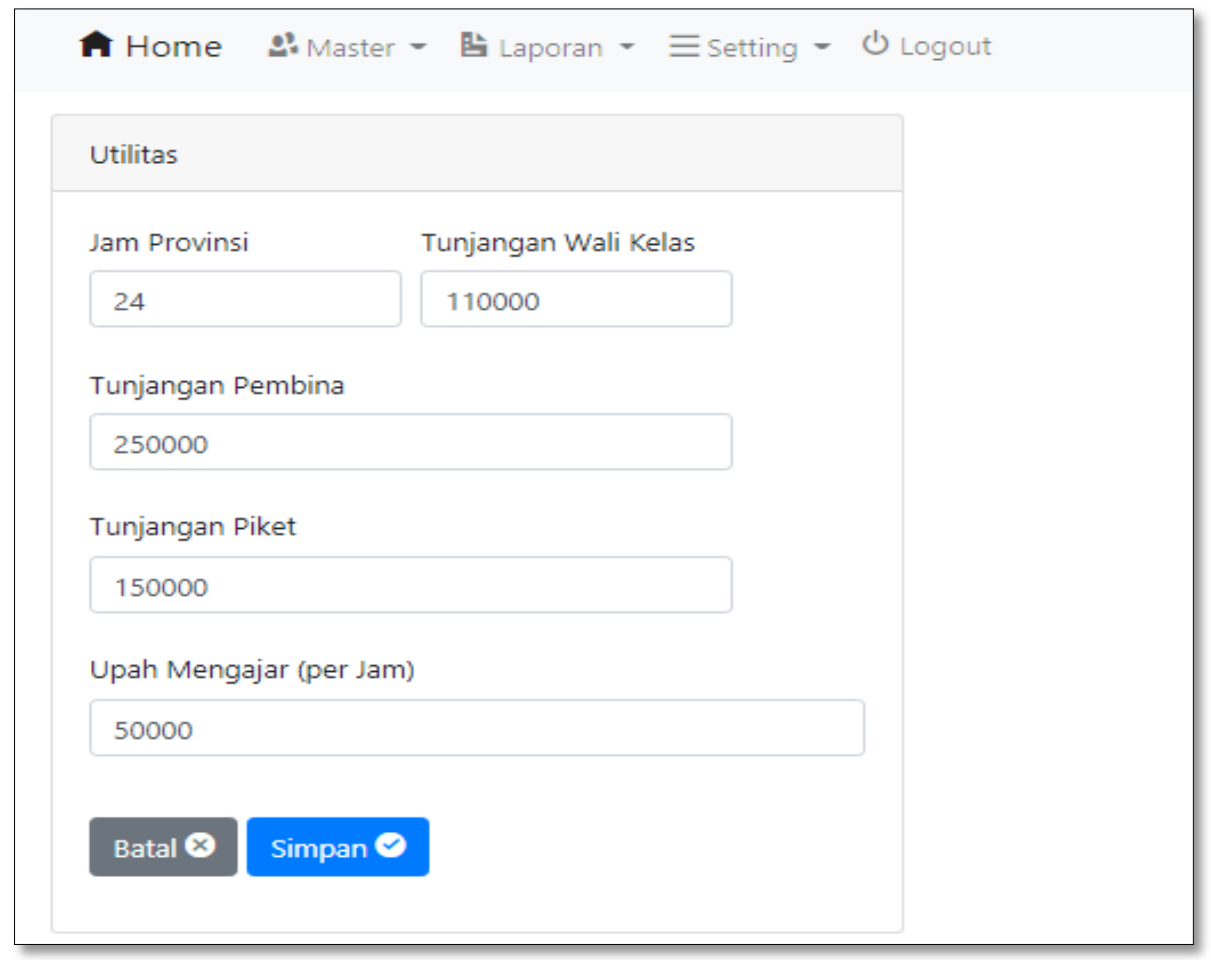

Gambar 16. Tampilan Menu Utilitas

\section{Penutup}

Pengolahan data yang terkomputerisasi sangatlah membantu instansi dalam memperoleh informasi secara tepat dan akurat. Dari penelitian yang terfokus pada sistem informasi manajemen honorarium ini dapat disimpulkan bahwa telah menghasilkan sebuah aplikasi yang mengelola honor pegawai lebih cepat, akurat dan mengurangi kesalahan. Serta dapat mempermudah berbagai 
aktivitas yang ingin dilakukan oleh user, baik dalam pemrosesan perhitungan maupun kemudahan dalam pencarian data histori atau arsip honorarium yang dapat dicetak dalam bentuk laporan.

\section{Daftar Pustaka}

[1] N. Dengen and H. R. Hatta, "Perancangan Sistem Informasi Terpadu Pemerintah Daerah Kabupaten Paser," Inform. Mulawarman, vol. 4, no. 1, pp. 47-54, 2009.

[2] R. B. Pratama, "Model Aplikasi Sistem Informasi Akuntansi Realisasi Anggaran Pada SMAN 1 Banjaran,"J. @ is Best, vol.3,no.1, 2018.

[3] K. Imtihan, R. Hadawiyah, and H. Asyari, "Sistem Informasi Penggajian Guru Honorer Menggunakan Konsep Agile Software Development dengan Metodologi Extreme Programming (XP) pada SMK Bangun Bangsa," Indones. J. Netw. Secur., vol. 7, no. 2, 2018.

[4] H. Hanafiah and A. Firmansyah, "Pembangunan Sistem Informasi Kepegawaian Berbasis Web di Kantor Desa Manggungharja," J. Sist. Inf. Karya Anak. Bangsa, vol. 1, no. 1, 2019.

[5] Gunardi and S. Ikhsan, "Sistem Informasi Honorarium Berbasis Web di Dinas Pemakaman dan Pertamanan Kota Bandung," J. Co Manag., vol. 1, no. 2, pp. 183-196, 2020.

[6] R. Dekas, "Pengaruh Pemberian Motivasi Dalam Bentuk Honorarium Terhadap Peningkatan Kinerja Karyawan Pada Dinas Sosial Kota Prabumulih," J. Manaj. dan Bisnis Sriwij., vol. 16, no. 4, 2018.

[7] A.-B. Bin Ladjamudin, Analisis dan Desain Sistem Informasi. Yogyakarta: Graha Ilmu, 2005.

[8] H. Jogiyanto, Analisis Dan Desain Sistem Informasi: Pendekatan Terstruktur, Teori Dan Praktik Aplikasi Bisnis. Yogyakarta: Andi, 2005.

[9] L. Hakim, Prinsip-Prinsip Dasar SISTEM INFORMASI MANAJEMEN. Jambi: Timur Laut Aksara, 2019.

[10] K. C. Laudon and J. P. Laudon, Management Information Systems, 12th ed. New Jersey: Pearson Prentice Hall, 2012.

[11] P. P. Widodo and Herlawati, Menggunakan UML: UML Secara Luas Digunakan Untuk Memodelkan Analisis \& Desain Sistem Berorientasi Objek. Bandung: Informatika, 2011.

[12] B. Sidik, Framework Codeigniter. Bandung: Informatika, 2012.

[13] J. Sofian and H. H. Solihin, "Pembangunan Aplikasi Sistem Informasi Surat Tugas Mengajar dan Surat Kerja Praktek pada Fakultas Teknik Universitas Sangga Buana Dengan Memanfaatkan Teknologi Framework Codeigniter," J. Techno-Socio Ekon., vol. 9, no. 1, 2016.

[14] J. Simarmata, Perancangan Basis Data. Yogyakarta: Andi, 2007.

[15] J. Recker, Scientific Research in Information Systems. Heidelberg: Springer, 2013.

[16] R. S. Pressman and B. R. Maxim, Software engineering: a practitioner's approach, Eighth. New York: McGraw-Hill, 2015. 